\title{
Potency of Carcinogens Derived from Covalent DNA Binding and Stimulation of DNA Synthesis in Rat Liver*
}

\author{
Werner K. Lutz, Marie-Therese Büsser, and Peter Sagelsdorff \\ Institute of Toxicology, Swiss Federal Institute of Technology and \\ University of Zurich, $\mathrm{CH}-8603$ Schwerzenbach, Switzerland
}

\begin{abstract}
In order to investigate the role of the stimulation of cell division for the initiation (and possibly promotion) of liver tumors by chemical carcinogens, the incorporation of radiolabelled thymidine into liver DNA was determined in male rats. Single doses of various levels of aflatoxin $B_{1}$, benzidine and carbon tetrachloride (all known to be genotoxic via DNA binding) did not affect cell division, whereas several hepatocarcinogens known not to bind to DNA (alpha$\mathrm{HCH}$, clofibrate, and 2,3,7,8-tetrachlorodibenzo-p-dioxin) gave rise to a dosedependent stimulation of liver DNA synthesis within $24 \mathrm{~h}$. An equation combining the influences of mitotic stimulation, expressed as dose required to double the control level of DNA synthesis, and DNA binding potency, expressed as the Covalent Binding Index, correlated well with the carcinogenic potency for both classes of hepatocarcinogens.
\end{abstract}

\section{INTRODUCTION}

The daily dose required to induce a given percent tumor incidence in a rodent life-time bioassay on carcinogenicity can vary about ten million-fold. Despite this wide range of potencies, short-term tests on carcinogenicity in general are evaluated only in a qualitative way, and therefore provide only a yes or no answer.

Every test gives rise to false positive and false negative results because it detects only one step out of a sequence of events ultimately leading to a tumor. A combination of various short-term tests is therefore bound to generate more and more false positive results so that, ad absurdum, all chemicals will produce one positive result if a large enough battery of tests is used. Faced with the conservative policy of regulatory agencies, the

* Presented at the Second International Symposium Sponsored by the Universities of Sassari and Cagliari. Session V: "Risk Assessment", October 12-15, 1983. Alghero, Italy. This Symposium section will be continued in Volume 12, Number 2. 1984 fear of producing a false positive result might be one reason for some reluctance to perform more than the minimum number of shortterm tests.

From a theoretical point of view, this approach is highly unsatisfactory; obviously, the more that is known about a chemical, the more reliable is its toxicologic evaluation. This problem could be solved if the shortterm data were analysed in a quantitative manner. Ames and coworkers (1) first calculated the number of Salmonella revertants per nmol test substance on the plate. This formed the basis for some preliminary attempts to correlate carcinogenic and mutagenic potencies (2). Subsequent analyses revealed that the correlation was very weak (3), producing a wave of criticism against all subsequent attempts to correlate potencies obtained from carcinogenicity bioassays with the results of short-term tests.

For some time we have been investigating the use of data on covalent binding of chemicals to DNA in vivo to estimate carcinogenic potency, and have defined a Covalent Bind- 
ing Index, $(\mathrm{CBI})=(\mu \mathrm{mol}$ chemical bound per mol DNA nucleotide) $/(\mathrm{mmol}$ chemical administered per $\mathrm{kg}$ body weight) (4). Data available from the literature and from our laboratory have been compiled in a review where it was shown that a semi-quantitative correlation between $\mathrm{CBI}$ and carcinogenic potency for hepatocarcinogens existed (5). Extension of the correlation to include organs other than the liver, and the use of carcinogenic potencies published as the daily dose required to induce a tumor in 50 percent of the animals treated for their life span $\left(\mathrm{TD}_{50}\right.$ values) revealed an astonishingly good correlation (6). Although the compounds used for that correlation were not intentionally selected, an inherent selection was still obvious because practically all compounds for which the necessary CBI data were available possessed structural characteristics which made them prone to be metabolized to chemically reactive derivatives. Only lately have DNA-binding assays been performed on a number of liver tumor-inducing agents where, to a detection limit of $\mathrm{CBI}<0.1$, no DNA binding was detectable $(7,8,9)$. A graphical representation of the new situation is given in Figure 1. It is obvious that the correlation has been weakened by the values in the lower right hand corner. The compounds on the bottom, therefore, are tumorinducing agents of various potencies whose mode of action is not related to DNA binding. The diagonal is occupied by those carcinogens with a mechanism of action characterized by DNA binding. The intermediate positions are filled by those compounds with carcinogenicity due to the combined effects of DNA binding and some type of cocarcinogenic or promoting activity.

With respect to the use of the CBI as a predictive measure for carcinogenic potency, this means that compounds with high CBI values are most likely strong carcinogens, whereas compounds with a CBI $<0.1$ are not necessarily non-carcinogenic or only weakly carcinogenic.

The question now arises as to whether the carcinogens shown not to bind to DNA exhibit some type of common biologiçal activity which could be assessed in a quantitative manner on a short-term basis. Among the many aspects discussed, the importance of cell division is often mentioned: firstly, to fix any promutagenic DNA lesion as a heritable mutation and thereby potentially initiate cell

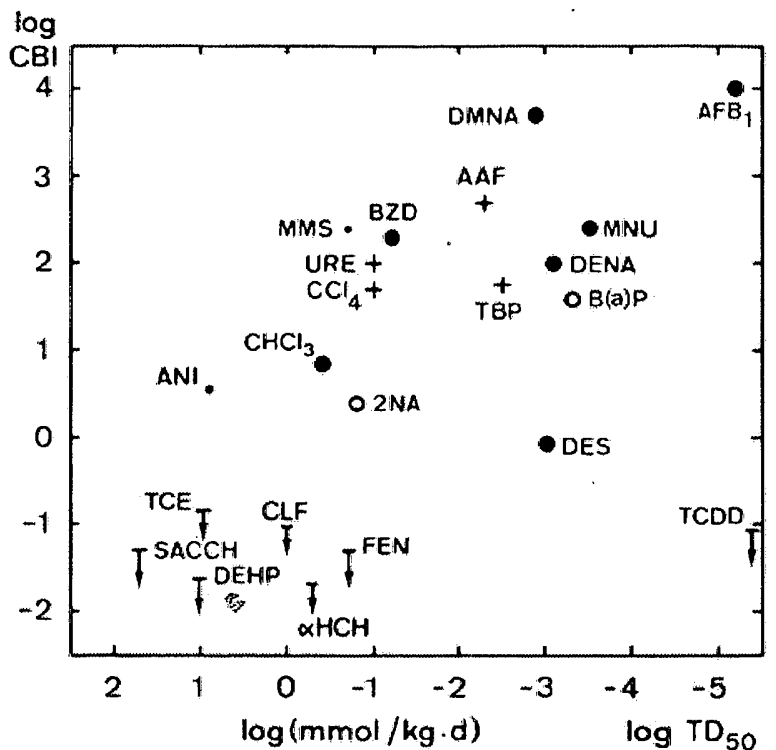

FIG. 1-Correlation of covalent DNA binding with carcinogenic potency. The chart published in Ref. 6 has been updated with the data points which have since become available. Abbreviations not used in the text: ANI, aniline; TCE, trichloroethylene; SACCH, saccharin; DEHP, di-(2-ethylhexyl)phthalate; MMS, methyl methanesulphonate; URE, urethane; 2NA, 2-naphthylamine; FEN, fenofibric acid; DMNA, dimethylnitrosamine; AAF, 2acetylaminofluorene; TBP, tris-(2,3-dibromopropyl)phosphate; MNU, N-methyl-N-nitrosourea; DENA, diethylnitrosamine; $B(a) P$, benzo(a)pyrene; DES, diethylstilbestrol.

transformation, and secondly, to provide some type of selective pressure during the long period of tumor promotion and progression. A refined experimental system to study the influence of chemicals on liver cell division in the rat has been used by SchulteHermann and coworkers (10). Their efforts were directed primarily towards an elucidation of the mechanism of cell transformation; we now tried to use their experimental setup to compare the ability of different hepatocarcinogens to stimulate DNA synthesis in rat liver. The value we searched for was the dose that was required to double the DNA synthesis rate within 24 hours (DD). Three dose levels were chosen for each hepatocarcinogen tested, the highest dose being around the $T D_{50}$, and the two lower doses were one tenth and one hundredth thereof.

\section{METHODS}

Young adult Sprague-Dawley rats [Iva:SIV50.SD] from Ivanovas, Kisslegg FRG, were kept singly in Macrolone cages. The illumi- 
nation time was from $5 \mathrm{am}$ to $5 \mathrm{pm}$. Food pellets in unlimited quantity were available only between $5 \mathrm{pm}$ and $10 \mathrm{pm}$, i.e., for five hours after the beginning of the dark phase, in order to synchronize liver cell division and thereby reduce the diurnal variability be. tween single animals. Drinking water was available at all times. After at least two weeks of acclimatization to the restricted dietary regimen, and ensuring that the body weight gain was back to normal., two animals per group were given at 4 am one single dose by gavage of one of six hepatocarcinogens in 0.5 $\mathrm{ml}$ solution. Three genotoxic agents were used: aflatoxin $\mathrm{B}_{1}\left(\mathrm{AFB}_{1}\right)$ in ethanol $\left(10^{-5}\right.$, $10^{-4}, 10^{-3} \mathrm{mmol} / \mathrm{kg}$ ), benzidine (BZD) in ethanol $(0.01,0.1,1 \mathrm{mmol} / \mathrm{kg})$, carbon tetrachloride (CCl4) in corn oil $(0.01,0.1,1 \mathrm{mmol} /$ $\mathrm{kg}$ ), and three hepatocarcinogens known not to bind appreciably to liver DNA: $\alpha$-hexachlorocyclohexane $(\alpha-\mathrm{HCH})$ in corn oil $(0.01$, $0.1,1 \mathrm{mmol} / \mathrm{kg}$ ), clofibrate (CLF) in corn oil $(0.01,0.1,1 \mathrm{mmol} / \mathrm{kg}), 2,3,7$, 8-tetrachlorodibenzo-p-dioxin (TCDD) in corn oil (only one dose of $10 \mu \mathrm{g} / \mathrm{kg}$, about $3 \cdot 10^{-5} \mathrm{mmol} / \mathrm{kg}$ ). Four control animals remained untreated. Food consumption during the following 5hour feeding period was $16 \pm 5 \mathrm{~g}$, spanning from $6.1 \mathrm{~g}\left(\mathrm{AFB}_{1}\right.$ low dose) to $23.1 \mathrm{~g}(\alpha-\mathrm{HCH}$ intermediate dose). At $04.00 \mathrm{~h}$ the following morning, i.e., 24 hours after the administration of the test compound, all animals were given $2 \mu \mathrm{Ci} / \mathrm{kg}$ [methyl ${ }^{14} \mathrm{C}$ ] thymidine (TdR, $61 \mathrm{mCi} / \mathrm{mmol}$; obtained from the Radiochemical Centre. Amersham, England) by gavage in $0.9 \%$ aqueous $\mathrm{NaCl}$. One rat of the highdose group of each compound was placed in an all-glass metabolism cage where a flow of $0.4 \mathrm{~L} / \mathrm{min}$ transported the air to a gas-washing bottle filled with ethanolamine/methanol, $1: 4$, in order to trap the carbon dioxide expired. Aliquots of this solution were counted for $\left[{ }^{14} \mathrm{C}\right]$ radioactivity after 1,2 , and 3 hours to check whether the bioavailability of the radiolabelled DNA precursor was more or less uniform amongst all individual animals. Four hours later, at $08.00 \mathrm{~h}$, the animals were killed by an ether overdose, the liver was excised and minced, and DNA was isolated from an aliquot by an abbreviated standard procedure (11), essentially by phenol extraction and hydroxylapatite adsorption chromatography. An aliquot of the DNA, eluted from the column with a high ionic strength buffer, was counted for radioactivity, and the amount of DNA was assessed on the basis of the UV absorbance at $260 \mathrm{~nm}$, taking an extinction value of 20 for a solution of $1 \mathrm{mg} / \mathrm{ml}$. The specific activity of the DNA (expressed in $\mathrm{dpm} / \mathrm{mg}$ ) was divided by the dose of radioactivity administered (expressed in $\mathrm{dpm} / \mathrm{kg}$ b.w.), and this value was multiplied by $309 \times$ $10^{6}$ in order to convert the data to the molar units of an incorporation index (II) $=(\mu \mathrm{mol}$ TdR incorporated per mol DNA-nucleotide)/ (mmol TdR administered per $\mathrm{kg}$ body weight).

\section{RESULTS}

Figure 2 summarizes the results obtained. It can be seen that none of the three DNAbinding agents, $\mathrm{AFB}_{1}, \mathrm{BZD}$, nor $\mathrm{CCl}_{4}$ stimulated cell division. Rather, there was some inhibition by $\mathrm{AFB}_{1}$ over the whole dose range, and by $\mathrm{CCl}_{4}$ or $\mathrm{BZD}$ with increasing dose only. The three hepatocarcinogens known not to interact with DNA, namely TCDD, CLF and $\alpha-\mathrm{HCH}$, gave rise to a three

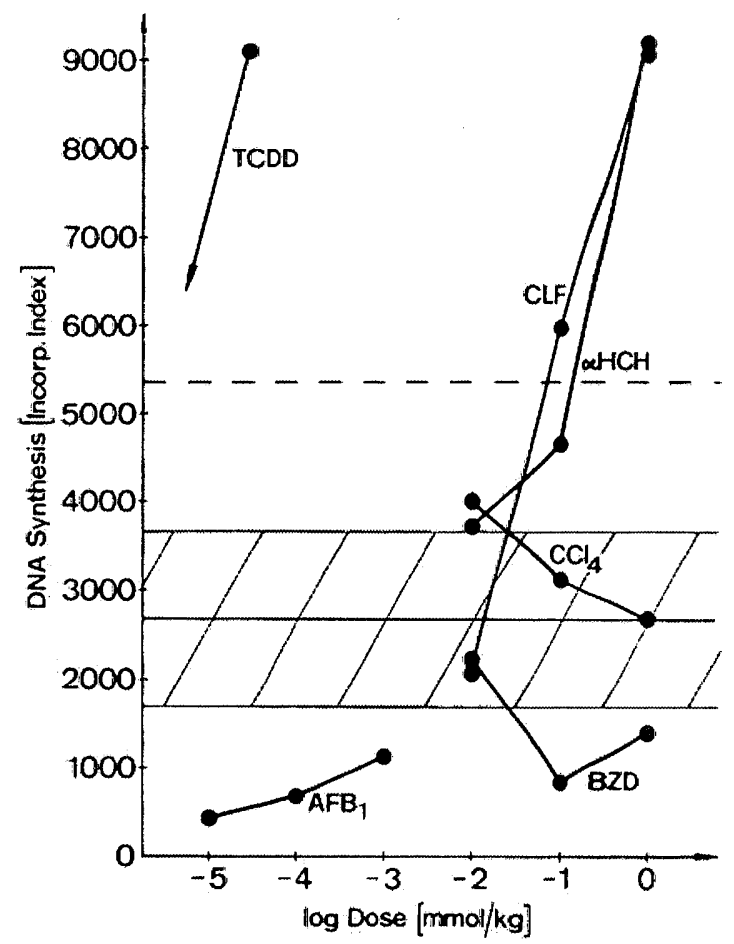

FIG. 2-Incorporation of [methyl- ${ }^{14} \mathrm{C}$ ] thymidine into rat liver DNA 24 hours after a single administration of various doses of hepatocarcinogens. The incorporation index is described in the Methods Section. All points represent means of two animals. The relative error (1 standard deviation) averaged over all duplicate determinations was 34 percent. The shaded area represents the incorporation index derived from 4 control animals $(2700 \pm 1000)$. The interrupted line is at the level of twice the control rate of DNA synthesis. 
to four fold stimulation of liver DNA synthesis at the highest dose level, and the intermediate dose of CLF and of $\alpha-\mathrm{HCH}$ produced approximately a doubling of the control level of DNA synthesis.

The shaded area covers a range of \pm 1 S.D. for the control DNA synthesis rates obtained from four animals. The variability, therefore, was relatively large despite the fact that the animals had been synchronized by a restricted feeding schedule. One part of the variability is probably due to different availabilities of the radiolabelled DNA precursor thymidine: The ${ }^{14} \mathrm{CO}_{2}$ recoveries in the air exhaled by the single animals within 3 hours after the oral administration of radiolabelled thymidine spanned from 7 to 16 percent of the radioactivity administered. Another reason for the large variations might have been the different food consumptions before sacrifice since a trend correlating food intake and DNA synthesis was observed. It will be important to investigate this effect in order to find out if food uptake alone could be used as a measure for the stimulation of liver DNA synthesis.

The dose required for each compound to bring about a doubling of the liver DNA synthesis (DD), is shown in Table I. For CLF and $\alpha-\mathrm{HCH}$, the intermediate dose used was taken for further calculations. For the three DNA-binding agents which were inactive at all dose levels tested, an extrapolation towards higher dose levels had to be performed with the assumption that the dose-response shape would be similar to the one seen with CLF and $\alpha-\mathrm{HCH}$. It was therefore assumed that aflatoxin would have to be administered in a theoretical dose level three orders of magnitude higher than the highest dose tested. For BZD, the points lay in the low standard deviation region of the set of control experiments; thus a shift of two orders of magnitude was assumed, and one step by a factor of ten was assumed to be required for carbon tetrachloride to reach a doubling dose. Due to acute toxicity, these extrapolated doses cannot be tested with animals.

Table I also summarizes data on hepatocarcinogenic potency and covalent binding to rat liver DNA. The values given in this Table do not represent exact values, but rather different orders of magnitude. The use of different strains and of different experimental protocols, for instance, can lead to uncertainties of \pm 2 orders of magnitude within subsets of different $\mathrm{TD}_{50}$ values calculated for the same carcinogen.(12). However, as the carcinogenic potency, the CBI, and the doubling dose for the stimulation of DNA synthesis span 6 to 7 orders of magnitude, this low accuracy is, nevertheless, sufficient for an evaluation of categories of different potencies.

Fig. 3 shows the correlation of carcinogenic potency with either CBI (top) or stimulation of liver DNA synthesis (DD) (bottom). In each representation one group of three hepatocarcinogens lies along a diagonal, thereby indicating a good correlation between the two variables, whereas the other group lies on the bottom of the diagram signalling that the two biological endpoints are completely unrelated. A mathematical analysis of the data presented in these charts must therefore produce the low correlation coefficients of $|\mathrm{r}|=$ 0.24 or 0.59 for the correlation between $T_{50}$ and $\mathrm{CBI}$ or DD. It is, however, promising that the compounds which fit with respect to CBI do not fit with respect to stimulation of DNA synthesis, and vice versa. This clearcut situation presenting two groups of chemicals essentially exhibiting two different modes of carcinogenic activity provides the basis for a significant improvement in the prediction of carcinogenic potency if the two correlations are combined in the general form of: Carcinogenic Potency $=$ DNA Binding $\times$ Stimula tion of DNA Synthesis; using, a multiple linear

TABLE 1-Set of Data Used in the Correlations of Carcinogenic Potency $\left(T_{50}\right)$ with Covalent DNA Binding (CBI) and/or the Dose Required to Double DNA Synthesis in Rat Liver (DD)

\begin{tabular}{llccc}
\hline $\begin{array}{c}\text { Hepato- } \\
\text { carcinogen }\end{array}$ & $\begin{array}{c}\mathrm{TD}_{\text {so }} \\
{[\mathrm{mmol} / \mathrm{kg} / \mathrm{d}]}\end{array}$ & $\begin{array}{c}\mathrm{CBI} \\
{[\mathrm{CBI} \text { units }]}\end{array}$ & Determined & $\begin{array}{c}\text { DD [mmol/kg] } \\
\text { Used in } \\
\text { Calculations }\end{array}$ \\
\hline AFB $_{1}$ & $6 \times 10^{-6}$ & 10000 & $>>10^{-3}$ & 1 \\
Benzidine & 0.07 & 200 & $\gg 1$ & 100 \\
CCl $_{4}$ & 0.1 & 50 & $>1$ & 10 \\
alpha-HCH & 0.5 & 0.02 & 0.1 & 0.1 \\
Clofibrate & 1 & $<0.1$ & 0.1 & 0.1 \\
TCDD & $2 \cdot 10^{-7}$ & $<0.1$ & $<3 \times 10^{-5}$ & $3 \times 10^{-5}$ \\
\hline
\end{tabular}



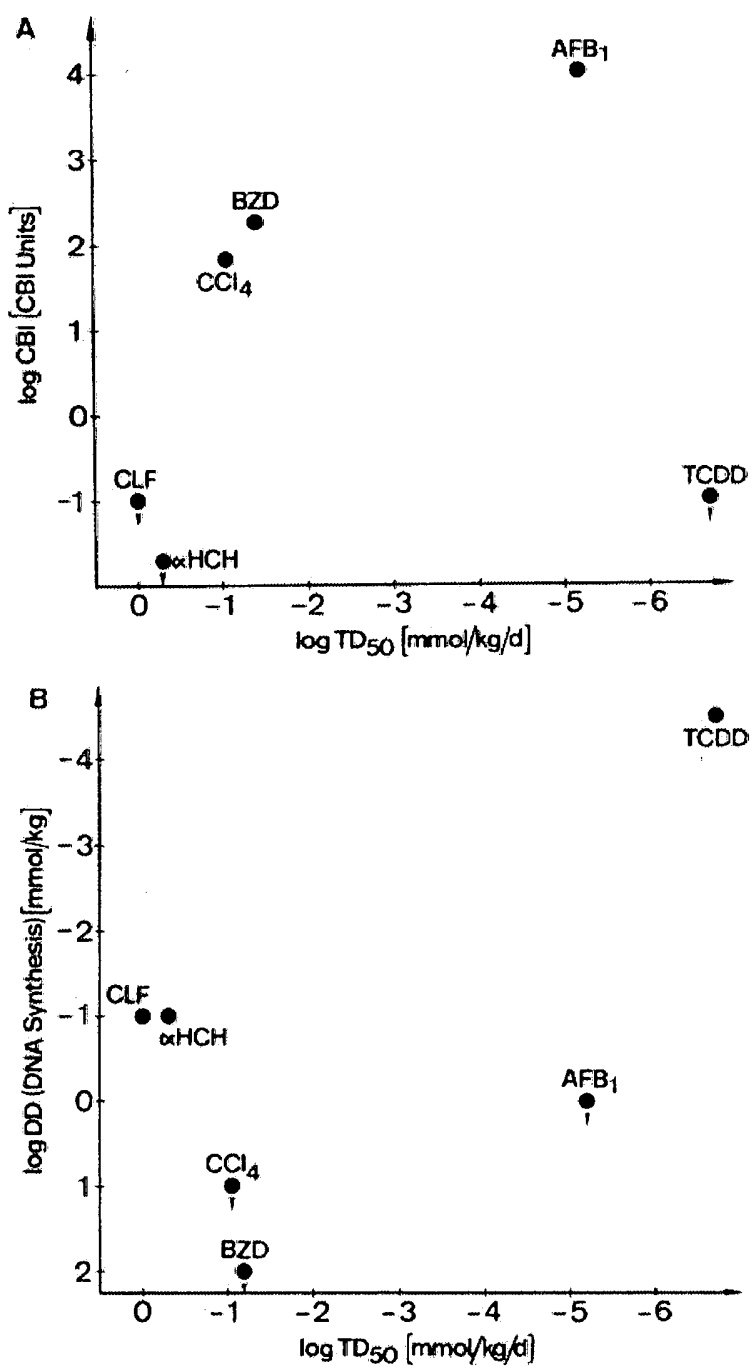

FIG. 3-Correlation of covalent DNA binding (CBI, top) and stimulation of liver DNA synthesis (DD, bottom) with carcinogenic potency for the six hepatocarcinogens tested.

regression analysis on the basis of their logarithms. The equation:

$$
\text { A) } \log T D_{5 s}=a_{0}+a_{1} \cdot \log C B I+a_{2} \cdot \log D D
$$

can be solved with the six data triplets given in Table I. The resulting equation:

B) $\log \mathrm{TD}_{50}=-0.6-1.2 \cdot \log \mathrm{CBI}+1.5 \cdot \log \mathrm{DD}$

has a high multiple linear correlation coefficient of $r=0.98$. It follows that a quantitative combination of the data obtained from two short-term tests measuring completely different biological events might provide a hitherto unseen predictive power to evaluate the potency of chemical carcinogens acting on different steps of the carcinogenic process. The coefficients $a_{1}$ and $a_{2}$ in the equation $A$ ) are of about equal magnitude. This means that both DNA binding for the genotoxic carcinogens and the stimulation of cell division for the other group of carcinogens studied here seem to possess similar importance in the entire process of tumor induction.

\section{DisCUSSION}

Parodi and coworkers (13) have shown that the prediction of a carcinogenic potency of a chemical carcinogen can be improved if the data obtained from two (or more) quantifiable short-term tests are combined. The best improvement is found if both tests correlate to some extent with carcinogenicity but poorly correlate with one another. This latter requirement is met by the combination used here: DNA binding and stimulation of DNA synthesis both are important parameters in the process of tumor initiation and promotion but are very different biological endpoints. A combination should therefore yield a substantial improvement in the attempt to assess carcinogenic potency because so far, established short-term tests have almost exclusively measured one or the other aspect of genotoxicity.

The data presented in this report are, however, highly preliminary and much work remains to be done before we can state that the system presented in this report does indeed reflect the type of stimulation of cell division which parallels the fixation of a premutational DNA lesion or signals some type of promoting activity. Caution is necessary because of the following observations:

First, the large inter-individual variabilities among control animals is a sign that we are dealing with a highly fragile equilibrium readily disturbed by a number of influences not necessarily related to the process of tumor formation. Among these variables, food intake might play an important role. Cytotoxicity with the regenerating processes elicited therefrom must also be controlled. Work by Schulte-Hermann on carbon tetrachloride showed, for instance, that a stimulation of DNA synthesis can be observed, but only 48 $h$ after its administration. More work will have to be directed into stabilizing the system and into investigating the influence of fasting, forced feeding, and hepatotoxicity.

Second, as a plane can be fitted perfectly onto any three points, the data base must be enlarged beyond six values to prove that the positive correlation obtained was not due to mere chance. More chemicals will have to be investigated and it will be interesting to de- 
termine if organs other than the liver also lend themselves to this type of analysis.

Third, more refined dose-response relationships must be established for all chemicals which are found to be positive in the broad dose range used here. The slope of the dose response and its relation to other variables, such as food consumption or cytotoxicity, will then be an additional criterion for evaluating the proposed mechanisms of hepatocarcinogens.

Other preliminary findings, however, make the system worthy of further investigation: The $\gamma$-isomer of $\mathrm{HCH}$, which is not a hepatocarcinogen, showed the same low DNA binding as $\alpha-\mathrm{HCH}$ in the CBI test (9), but did not stimulate liver DNA synthesis. Thus, the present system was able to discriminate biological activities on the basis of relatively subtle stereochemical differences. Therefore, there is justified hope that a quantitative assessment of the potency of chemical carcinogens, one of the most important criteria for any risk assessment, will become possible on the basis of a combination of short-term tests. The choice of the most appropriate test battery will be determined by the elucidation of the most critical biological events which govern the process of chemical carcinogenesis.

\section{ACKNOWLEDGEMENT}

We are indebted to the 'Krebsliga des Kantons Zürich' for the graduate fellowship awarded to M.-T.B. We thank Ms. Sarah Shephard for her help with the English translation.

\section{REFERENCES}

1. McCann J, Choi E, Yamasaki E and Ames BN (1975) Detection of carcinogens as mutagens in the Salmonella/microsome test: Assay of 300 chemicals. Proc Natl Acad Sci (USA) 72:5135-5139.

2. Meselson $M$ and Russell K (1977): Comparisons of carcinogenic and mutagenic potency, In: Origins of Human Cancer., HH Hiatt, ID Watson and JA Winsten (eds). Cold Spring Harbor Laboratory, pp. 1473-1481.

3. Ashby J and Styles JA (1978): Does carcinogenic potency correlate with mutagenic potency in the Ames assay? Nature 271:452-455.

4. Lutz WK and Schlatter C (1977): Saccharin does not bind to DNA of liver or bladder in the rat. ChemBiol Interact 19:253-257.

5. Lutz WK (1979): In vivo covalent binding of organic chemicals to DNA as a quantitative indicator in the process of chemical carcinogenesis. Mutat Res 65:289-356.

6. Lutz WK (1982): Constitutive and carcinogen-derived DNA binding as a basis for the assessment of potency of chemical carcinogens. In: Biological Reactive Intermediates, Vol. II Part B., R Snyder, DV Parke, II Kocsis, DJ Jollow, GG Gibson and CM Witmer (eds). Plenum Press, New York, pp. 13491365.

7. Poland $A$ and Glover $E$ (1979) An estimate of the maximum in vivo covalent binding of $2,3,7,8$-tetrachlorodibenzo-p-dioxin to rat liver protein, ribosomal RNA, and DNA. Concer Res 39:3341-3344.

8. von Däniken A, Lutz WK and Schlatter C (1981): Lack of covalent binding to rat liver DNA of the hypolipidemic drugs clofibrate and fenofibrate. Toxicol Letters 7:305-310.

9. Sagelstorff P, Lutz WK and Schlatter C (1983): The relevance of covalent binding to mouse liver DNA to the carcinogenic action of hexachlorocyclohexane isomers. Carcinogenesis 4:1267-1273.

10. Schulte-Hermann $\mathrm{R}$ (1974): Induction of liver growth by xenobiotic compounds and other stimuli. Crit Rev Toxicol 3:97-158.

11. Viviani $A$ and Lutz WK (1978): Modulation of the binding of the carcinogen benzo(a)pyrene to rat liver DNA in vivo by selective induction of micro. somal and nuclear aryl hydrocarbon hydroxylase activity. Cancer Res 38:4640-4644.

12. Parodi S, Taningher $M$ and Santi L (1982): Aikaline elution in vivo: Fluorometric analysis in rats; quantitative predictivity of carcinogenicity as compared with other short-term tests. Banbury Report Vol. 13. Cold Spring Harbor Laboratory, pp. 137-155.

13. Parodi S, Taningher M, Boero P and Sariti L (1982): Quantitative correlations amongst alkatine DNA fragmentation, DNA covalent binding, mutagenicity in the Ames test and carcinogenicity, for 21 compounds. Mutat Res 93:1-24. 